\title{
Analysis of interaction between waves and cliff along the Adriatic coast of Polignano (Apulia, Italy)
}

\author{
Giuseppe Spilotro ${ }^{1}$, Roberta Pellicani ${ }^{1}$, Rossella Pagliuca², Marco Mucciarelli², Marcello \\ Bianca $^{2}$, Daniela Miccoli² \\ ${ }^{1}$ Department of European and Mediterranean Cultures, University of Basilicata, Italy \\ ${ }^{2}$ School of Engineering, University of Basilicata, Italy
}

\begin{abstract}
The aim of this study is the analysis of the dynamic behavior of rocky cliff located below the old urban center of Polignano (Apulia, Southern Italy). In order to characterize the behavior of the cliff under the impulse generated by sea waves, two types of measures were carried out on the rocky mass: (1) environmental vibrations and (2) accelerometer records. The first type of measures, which may be executed in a short time with a high spatial density, has provided a recognition of the different types of dynamic behavior of the cliff.

The accelerometer records, carried out during heavy storms in December 2009 and January 2010, have been allowed to confirm the results of previous measures and to evaluate the energy transfer from waves to cliff, in terms of maximum values and temporal distribution.

In order to facilitate a correct interpretation of measures, geological surveys for studying fracturation of rocky mass were carried out.

The main results were the following:

1. The cliff shows a subdivision into two zones: (a) with stable behavior and without amplification of wave impulse, characteristic of limestones, (b) with amplification of wave impulse along several preferential directions, some of which are substantially coincident with the directions of main systems of fractures, while others coincide with local orientation of the rocky cliff.

2. The accelerometer measures confirm the different behavior. The most stable and less fractured zone is crossed by the energy transmitted from waves to cliff without giving its own contributions, the other zone filters this energy with its own frequencies.

3. The accelerations recorded (with maximum value of about $0.02 \mathrm{~g}$ ) on the cliff during storms show a regular distribution of observed values; this distribution can be correlated with the wave height offshore.

\section{Introduction}

Much of the rocky cliff coast line of southern Italy and particularly Apulia region suffers from cliff failure phenomena, which, in the presence of beach at the cliff toe, constitute a risk to person life. Cliff failures are predominately linked with the lithology, the structure of the rocky mass as well as the weather conditions and the wave action [1].

In the coastal area, the analysis about the morphological evolution and instability, that affect the cliffs, requires understanding of the complex framework of interactions between the internal characteristics of the coastal system and the external stresses.
\end{abstract}


The factors, affecting intrinsically the stability of cliffs, are therefore all of those typical continental, such as the lithostratigraphic, structural, morphological settings (slope and aspect of the wall, etc..) and the hydrogeology and the mechanical properties of rocky mass. The external factors are, however, represented by impact of sea waves, currents and tides, as well as meteorological agents, the biological activity of marine microorganisms and, finally, by human activities.

The rocky coasts of Apulia Region are very often constituted by layered and fissured carbonate rocks, which are affected also by the effect of water circulation and long-term karst.

The analysis of the destabilizing effect exercised by the waves on the cliff does not stop with the only assessment of the most violent storms occurred in the examined area, but it is necessary to examine the frequency of the wave motion, since just the not very energetic but extremely continuous waves cause the erosion of the coastal slopes, also associated with mechanisms of failure, due to cyclic stresses, of the rocky mass.

The impact of the waves and the sea currents on the cliff also depends on the conformation of the seabed, able to mitigate the effect of wave trains or, conversely, to concentrate the energy only in some zones of the coast.

Another important factor is the orientation of the coast line respect to the wave fronts, because the actions and the energy, that they transmit on the cliff, depend not only on characters of the waves, but also on the direction of propagation; it is a function of the height of breaking wave and the angle between the wave front and the coast. So, as the direction of propagation results to be orthogonal to the coastline, the higher will be the energy that is transferred by waves on the coastal wall.

The present work is aimed to establish the dynamic behavior of rocky cliff, located below the old urban center of Polignano (Apulia region, Southern Italy) under the impulse generated by sea waves. The study area is located in a stretch of Adriatic coast of Apulia; the morphology of the urban area is represented by a coastal platform slightly sloping to the sea, with an altitude ranging from about $27 \mathrm{~m}$ a.s.l. (internal area) to about $12 \mathrm{~m}$.

This work was divided into two phases. The first is consisted in geomechanical survey, aimed to underline the main discontinuity families into the rocky mass, using the Markland's test for the analysis of the potential failure mechanisms [2]. The second phase was focused on the characterization of the dynamic behavior of the cliff under the impulse generated by sea waves. Two types of measures were carried out on the rocky mass: (1) environmental vibrations and (2) accelerometer records. The first type of measures, which may be executed in a short time with a high spatial density, has provided a recognition of the different types of dynamic behavior of the cliff. The accelerometer records, carried out during heavy storms in December 2009 and January 2010, have been allowed to confirm the results of previous measures and to evaluate the energy transfer from waves to cliff, in terms of maximum values and temporal distribution.

\section{The study area}

The urban area of Polignano a Mare is located in a stretch of the Adriatic coast of Apulia, characterized by an alternation of inlets, bays, headlands and cliffs (Fig. 1a). Sea caver are also frequent; they are due to karst events. The morphology of the study area is represented by a coastal platform weakly sloping to the sea, with an altitude ranging from $27 \mathrm{~m}$ a.s.1. to $12 \mathrm{~m}$ a.s.l.

The morphology of Polignano's cliff is complex, with the presence of bays and headlands. The oldest part of the town is situated on a promontory which extends towards the sea in the direction approximately N-S. The headland is bordered, to the west, by a deep incision of fluvial origin (locally known as "lama"), whose mouth is currently engaged by deposits of beach. The rocky cliff, that characterizes all part of coastal urbanized, shows the presence of many caves 
whose development is related to the interaction between the widespread karst events, typical for the carbonate coast of Apulia, and the erosive action of waves. An important predisposing factor is the presence of various sub-systems of sub-vertical fractures which, with sub-horizontal layers of limestone, divide the rocky mass of the cliff into blocks potentially unstable.

The geological formations outcropping in the study area belong to the tectonicstratigraphic domain of Apulian platform, which represents the foreland sector of the Apennine orogeny. The stratigraphic succession in the study area is formed by the following formations (Fig.1b):

- "Tufi delle Murge": mainly formed by sandy calcareous deposits and sandy-alcareousclayey deposits, with a variable degree of cementation and with a stratification not much evident.

- "Calcare di Bari": sedimentary complex, deposited in a palaeogeographic environment of internal carbonate platform and constituted of: 1) dolomitic limestone, 2) micritic limestones and 3) white bioclastic limestones, with variable degree of cementation. It is generally well-stratified into layers and crossed by several systems of tectonic subvertical discontinuity in correspondence of which karst events occur.

The first formation has a thickness of about 11-12 $\mathrm{m}$ at the cliff.

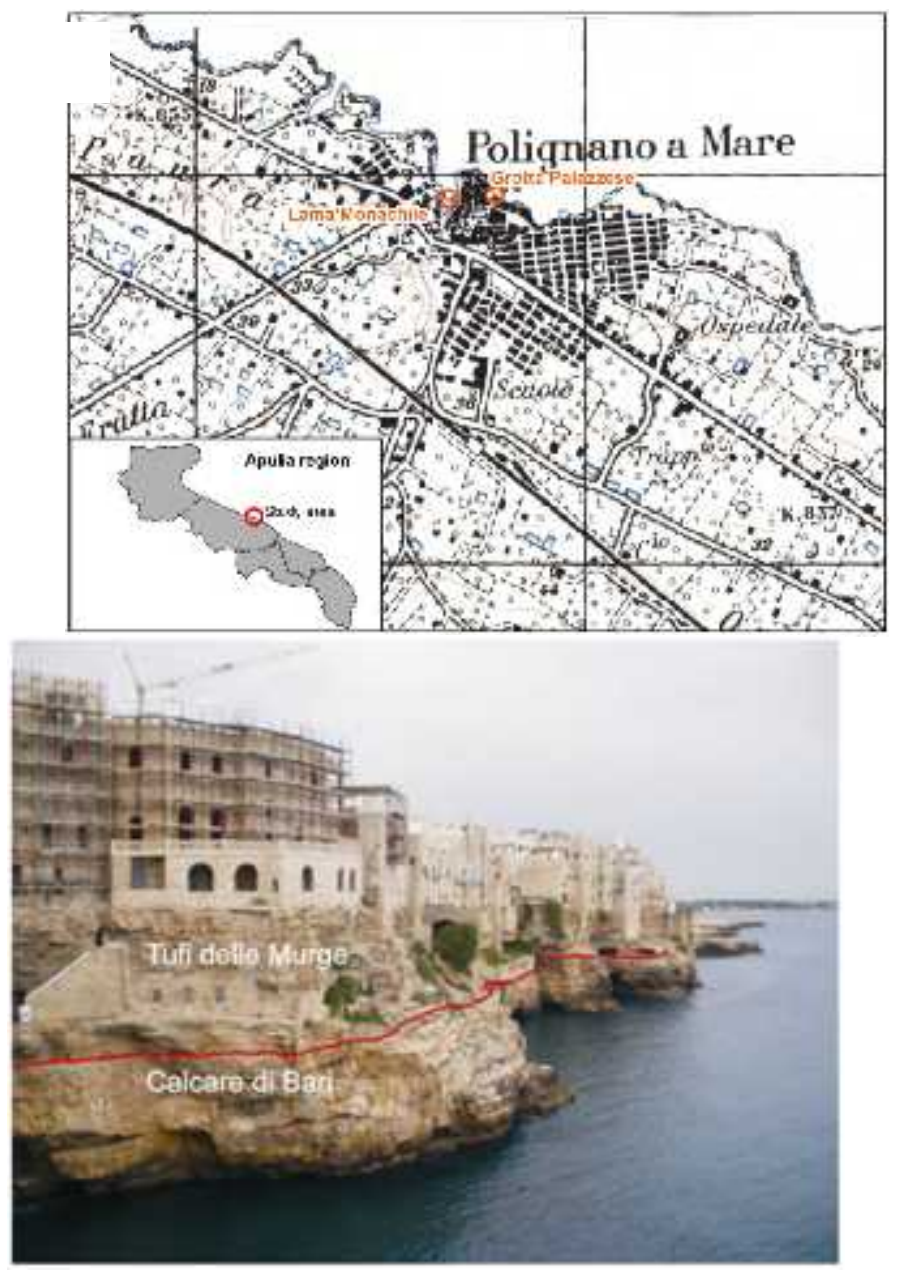

Figure 1 The study area: (a) location in Apulia region and indication of the sample sites; (b) Stratification of the rocky cliff, with "Tufi delle Murge" formation lying above "Calcare di Bari" 


\section{Methodology}

\section{Geo-structural settings}

The analyses have been performed at following three sites: (a) east side of Lama Monachile, (b) west side of Lama Monachile (c) cave in Grotta Palazzese (Fig 1a). In order to evaluate the conditions of stability of rocky cliffs, several geomechanical relieves of discontinuity was performed along eight scan lines: S1, S2, S3 and S4 on the east side of Lama Monachile; S5 and S6 on the west side of Lama Monachile; S7 and S8 at Grotta Palazzese. The kinematic analysis have been carried out by using the Markland's test (1972), in order to analyze the potential failure mechanisms (topple, plane slide and wedge slide) (Table 1).

Table 1 Geomechanical parameters of discontinuity families used in Markland's test

\begin{tabular}{|c|c|c|c|}
\hline $\begin{array}{r}\text { Dip } \\
\text { direction }\end{array}$ & ip & $\begin{array}{l}\text { Discon } \\
\text { tinuity }\end{array}$ & Typology \\
\hline \multicolumn{4}{|c|}{ East side of Lama Monachile } \\
\hline 200 & 9 & 01 & Joint \\
\hline 224 & 0 & 02 & Joint \\
\hline 360 & 2 & 03 & Joint \\
\hline \multicolumn{4}{|c|}{ West side of Lama Monachile } \\
\hline 143 & & 04 & $\begin{array}{l}\text { Stratificatio } \\
n\end{array}$ \\
\hline 217 & 2 & 05 & Joint \\
\hline 27 & 0 & 06 & Joint \\
\hline 102 & 9 & 07 & Joint \\
\hline 126 & & 08 & $\begin{array}{l}\text { Stratificatio } \\
\mathrm{n}\end{array}$ \\
\hline 240 & 3 & 09 & Joint \\
\hline \multicolumn{4}{|c|}{ Grotta Palazzese } \\
\hline 90 & 9 & 10 & $\begin{array}{l}\text { Stratificatio } \\
n\end{array}$ \\
\hline 43 & 6 & 11 & $\begin{array}{l}\text { Stratificatio } \\
\mathrm{n} / \text { Joint }\end{array}$ \\
\hline 360 & 7 & 12 & $\begin{array}{l}\text { Stratificatio } \\
\text { n/Joint }\end{array}$ \\
\hline
\end{tabular}


The results are shown in Figure 2. According to the Markland's test, for the east side of Lama Monachile, none of the discontinuity falls in the range of instability for topple and plane slide. While the wedge slide represents the type of failure mechanism more likely in the case of cliff with a slope greater than $65^{\circ}$. For the west side of Lama Monachile, the type of failure mechanism more likely is the topple and wedge slide. The Markland's test, for Grotta Palazzese, has been performed with reference to the three free surfaces with orientation 90/5, 90/85 and $360 / 85$. The test did not show potential instability.

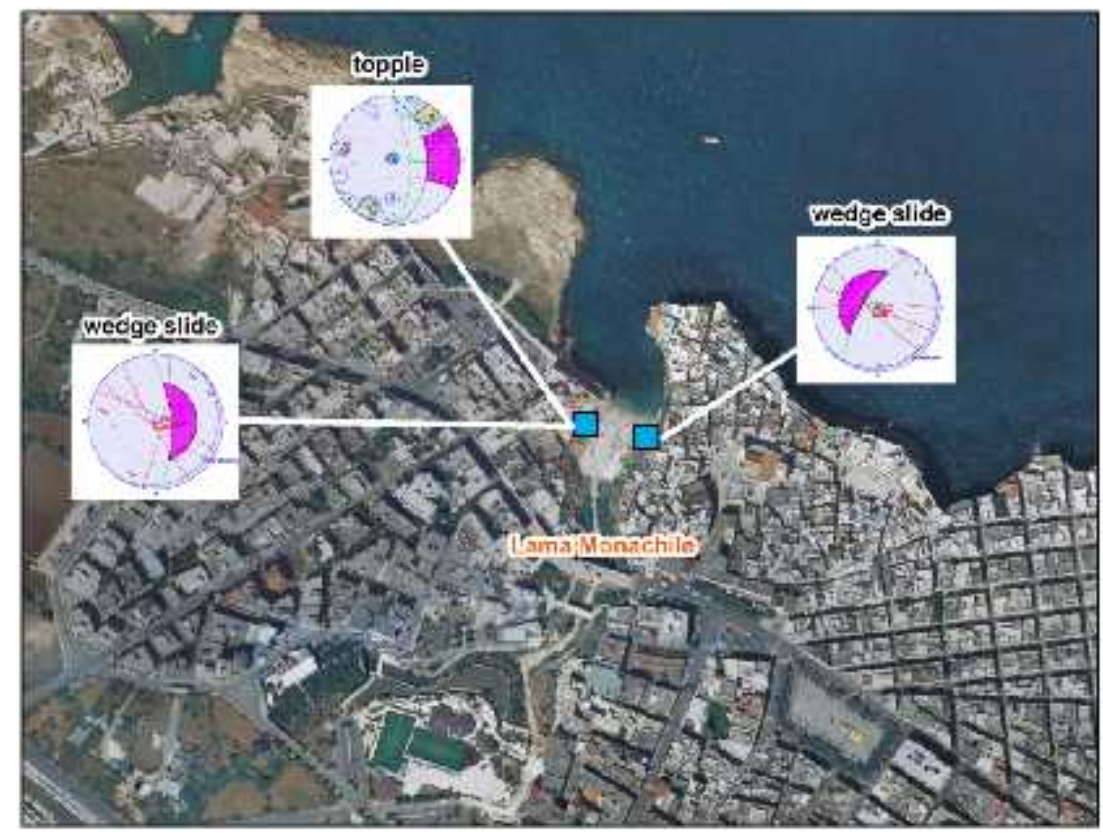

Figure 2 Potential mechanisms of instability for the cliff in Lama Monachile site

\section{Monitoring of cliff dynamic behavior}

In order to characterize the behavior of the cliff under the impulse generated by sea waves, two types of measures were carried out on the rocky mass: (1) environmental vibrations and (2) accelerometer records. The first type of measures, which may be executed in a short time with a high spatial density, has provided a recognition of the different types of dynamic behavior of the cliff.

The geophysical survey technique HVSR (Horizontal to Vertical Spectral Ratio) is based on the analysis of spectral ratios between the horizontal components and the vertical component of the ground motion, caused by seismic forces generated by earthquakes or environmental vibrations. The aim of HVSR technique is identifying the resonance frequencies of the soil and the relative directions (controlled by the rocky mass structure). During the geophysical survey, based on an analysis of environmental noise, have been carried out 38 measures of environmental vibration, each one lasting 12 minutes (Figure 3). During the processing phase, the original measurements have been "cleaned" (by analyzing the graphs H/V TIME HISTORY) by peaks caused by temporary disturbances and, therefore, not associated to the physical characteristics of the soils investigated. In the final processing of the measures, has been used a sampling frequency of $128 \mathrm{~Hz}$, with window $10 \mathrm{sec}$ and a smoothing percentage of $5 \%$.

The accelerometer records, carried out during heavy storms in December 2009 and January 2010, have been allowed to confirm the results of previous measures and to evaluate the energy transfer from waves to cliff, in terms of maximum values and temporal distribution.

Generally, the PGA (Peak Ground Acceleration), identifies the measure of the maximum acceleration recorded to the ground and can be representative of the movement occurred in a 
single geographical area. In this work the PGA value is considered as the intensity produced by the impact of a wave on the rocky cliff. Near the coast have been positioned two accelerometers, which have been recorded the accelerations along the three directions (Z, North-South and EastWest), where the NS and EW components represent the motion in the horizontal plane and the Z component represents the motion in the vertical plane. Records have been carried out in two different sites, Polignano Covo, at West, and Grotta Palazzese (inside the cave), at East (Fig. 3).

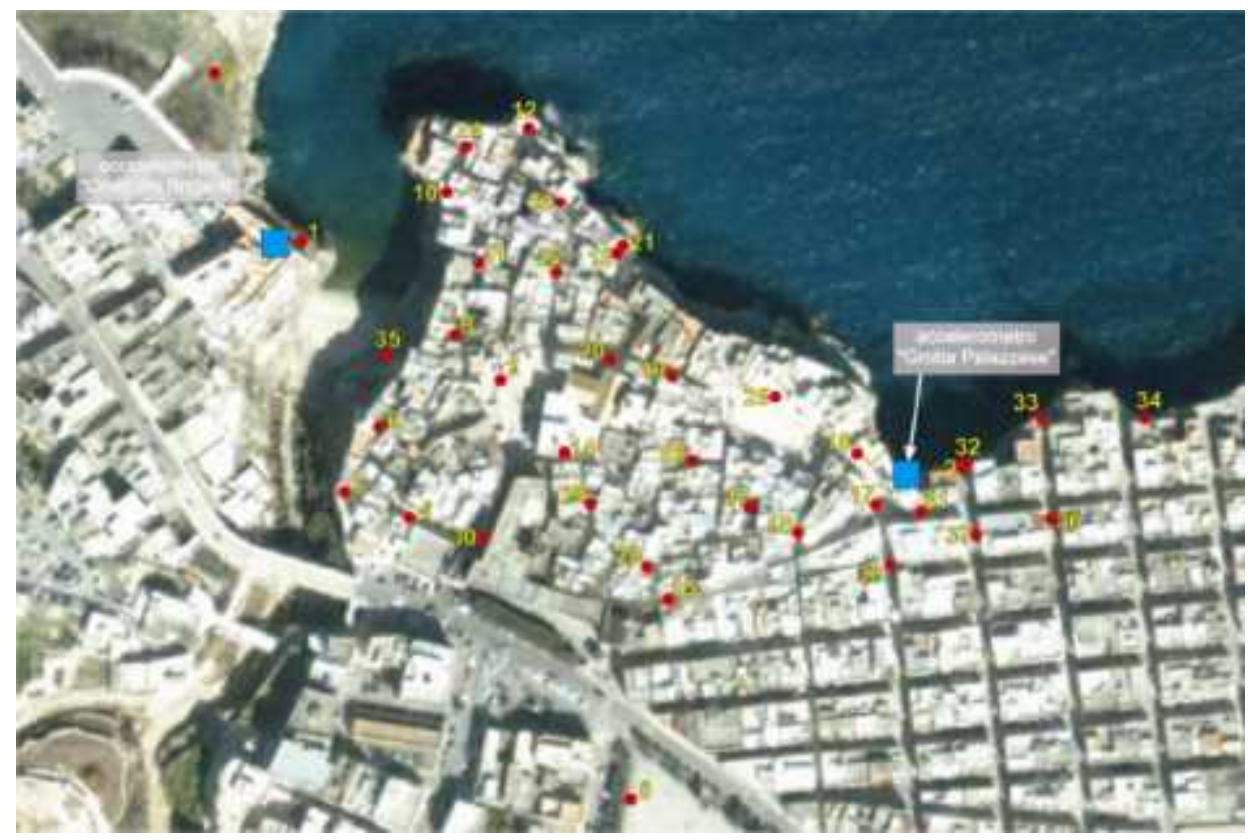

Figure 3 Location of 38 points for measuring environmental vibrations (red points) and 2 accelerometers (blue square)

The accelerometer monitoring was carried out from 13th December 2009 to 11th January 2010. Among these, a subsample of 11 days has been analyzed, during which the most significant sea storms were occurred. For each day, an average of four accelerometer recordings were considered. The 9th and 10th December 2009 and 16th January 2010 are the only days, affected by storms, showing a number of significant accelerograms.

For Grotta Palazzese site only three days are available; they are: from $7^{\text {th }}$ to 22 th and 24 th December 2009. Each accelerometric recording was analyzed through the use of Matlab, in order to identify the maximum values of PGA, Arias' Intensity and Housner's Intensity. For all recordings a polar diagram has been generated, useful to assess the preferential direction of the intensities at the cliff.

\section{Results}

The results obtained from the HVSR measures, related to the presence or not of phenomena of local seismic amplification were summarized in Figure 4. It is evident that the measures characterized by a peak of amplification are concentrated along the strip of 
promontory nearest to the cliff. The measurements performed in internal zones of the headland and along the eastern side of cliff do not show any peak of amplification.

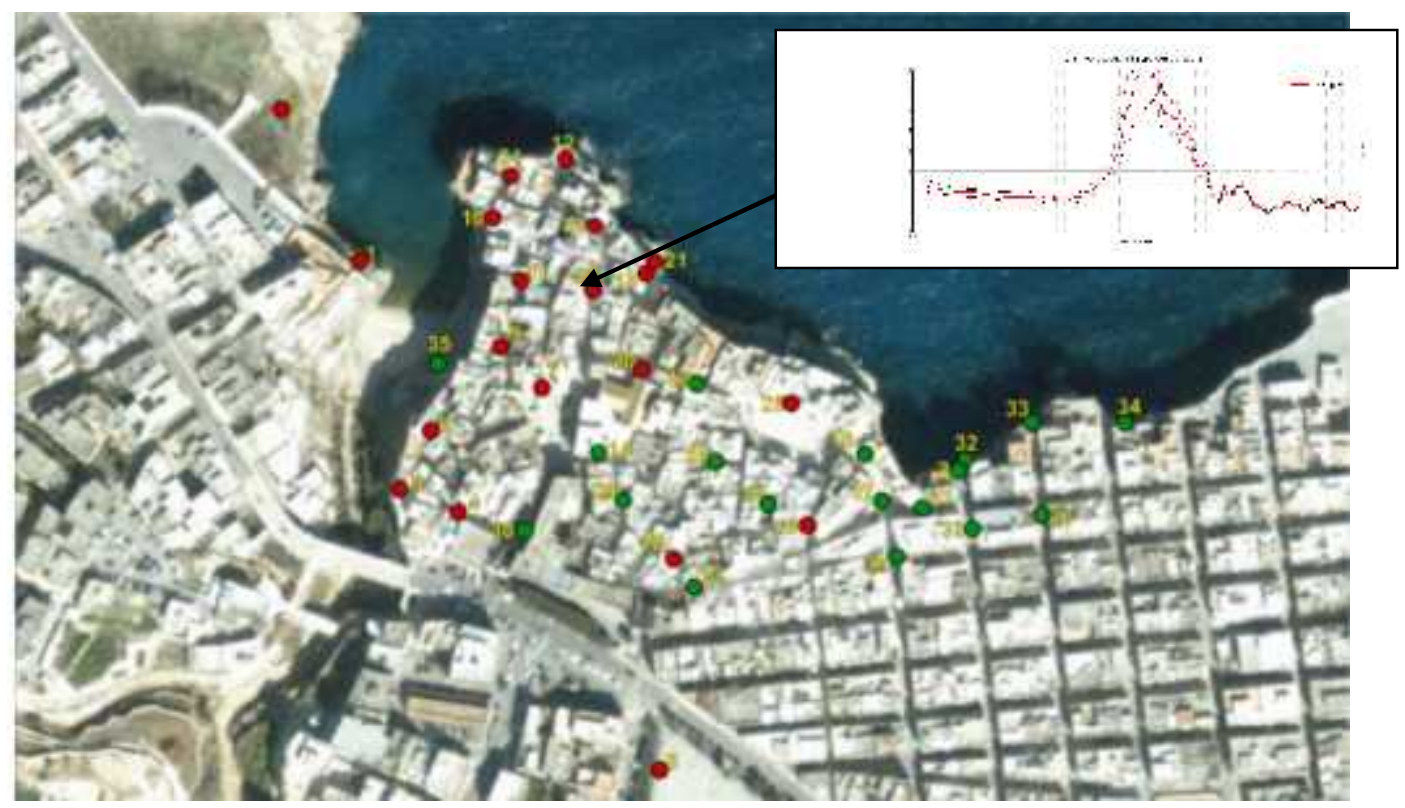

Figure 4 Measures of environmental vibration: red points are characterized by amplification (HVSR graph in the figure); green points are not characterized by amplification

Another important result, obtained by the analysis of environmental noise measurements, is represented by the graphs which show the azimuthal directionality of amplification frequency (directional $\mathrm{H} / \mathrm{V}$ ). They indicate whether an amplification frequency is linked to a particular geological structure or if it presents an isotropic distribution in the soil.

The distribution of the preferential directions of amplification frequencies (those characterized by a peak of amplification) is shown in Figure 5a.

In Figure $5 \mathrm{~b}$ are shown the stereo plot that summarize the orientations of the main systems of fractures detected at two structural stations located at east and west sides of Lama Monachile site.

The cliff shows a clear differentiation into two zones, one with stable behavior and not amplifying the seismic/wave motion (tabular limestones), and another one that shows an amplification of sea wave motion along preferential directions. Several of these directions substantially coincide with the directions of the main systems of fractures.

The accelerometric monitoring has allowed to determine not only the values of accelerations vs. time, due to the impact of waves on the cliff, but also the following characteristic parameters of movement: the rotational Arias' Intensity $(\mathrm{m} / \mathrm{s})$ with corresponding velocity and direction and the rotational Housner's Intensity with corresponding directions.

All the obtained results were represented in a single diagram, in order to evaluate if the two intensity values, for all the recording days, are distributed along the preferential directions 
of movement amplification, coinciding with the main families of fractures present in the rocky cliff.
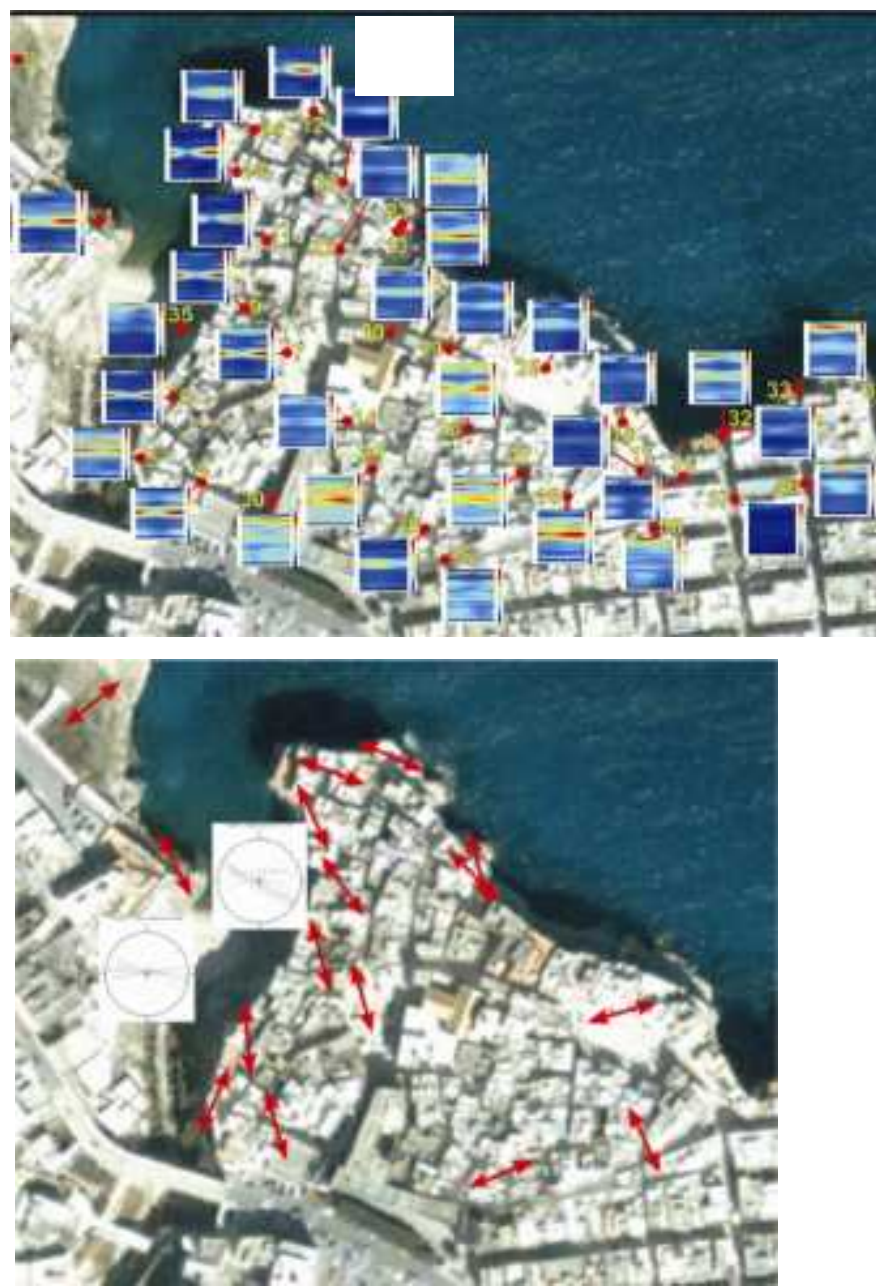

Figure 5 (a) Directionality of H/V; (b) Distribution of preferential directions of amplification frequencies and steroe plot of discontinuities

In Figure 6 the distribution of the preferential directions of amplification frequencies is compared with the distribution of maximum and minimum Arias' and Housner's Intensity, recorded at two sites: Polignano Covo, at West, and Grotta Palazzese, at East.

In Polignano Covo site, the distribution of Arias' and Housner's Intensity coincides with the distribution of preferential directions of amplification frequencies of the cliff and also with the main families of fractures in the eastern side of the rocky mass. In particular, the maximum values of the two intensities are distributed along the NW direction. While the minimum values are distributed preferentially along the SW direction.

Also for Grotta Palazzese site, the distribution of the two intensities is mainly coincident with the distribution of preferential directions of amplification frequencies of the cliff. The maximum values are distributed along the SW direction and the minimum values are distributed along NW. 


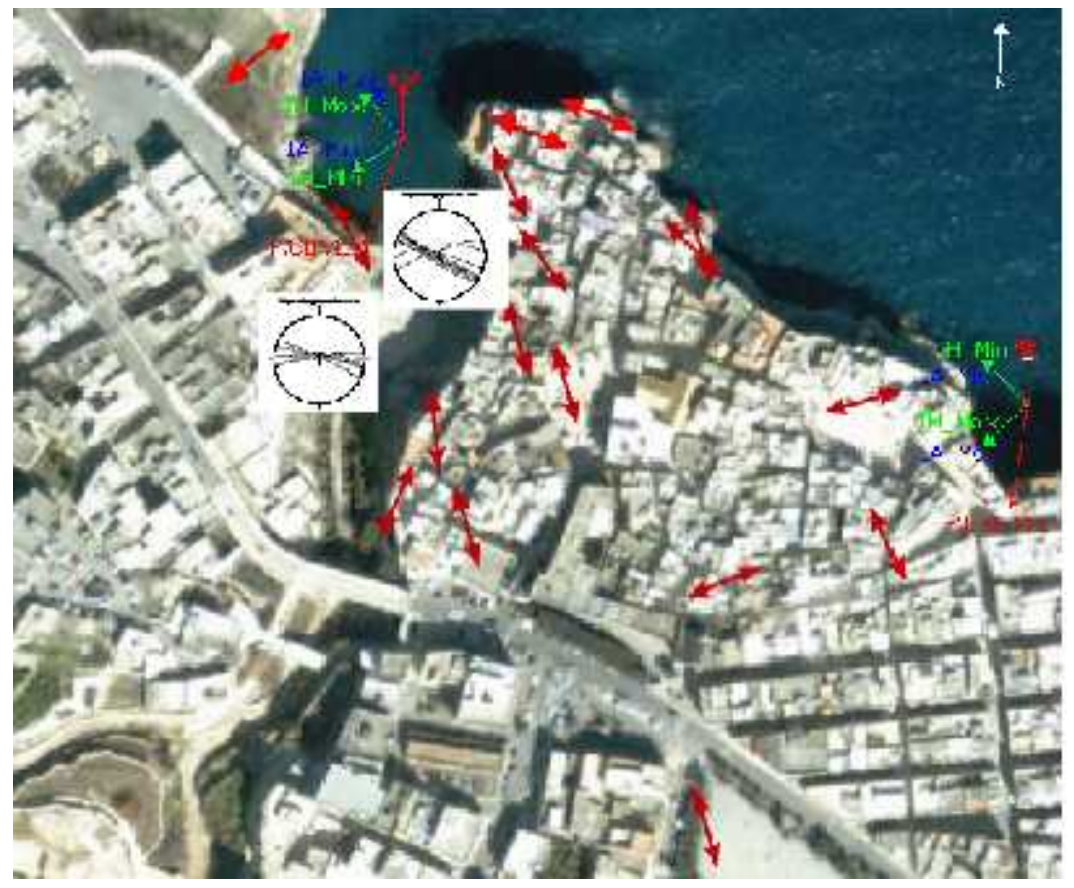

Figure 6 Comparison between the directions of the amplification frequencies and those of Intensities of Arias and Housner (maximum and minimum)

Finally, we have analyzed the directions of the waves occurred in the days corresponding to the registration of maximum values of acceleration and Housner's Intensity. The higher values of acceleration correspond to an average direction of wave propagation almost or entirely orthogonal to the cliff.

\section{Conclusions}

In this work the interaction between waves and rocky cliffs in the urban area of Polignano (Apulia, Italy) has been studied. In particular, the effect of the transfer of the wave breaking energy on the cliff has been analyzed.

The main results were the following:

1. The cliff shows a subdivision into two zones: (a) with stable behavior and without amplification of wave impulse, characteristic of limestones, (b) with amplification of wave impulse along several preferential directions, some of which are substantially coincident with the directions of main systems of fractures, while others coincide with local orientation of the rocky cliff.

2. The accelerometer measures confirm the different behavior. The most stable and less fractured zone is crossed by the energy transmitted from waves to cliff without giving its own contributions, the other zone filters this energy with its own frequencies.

3. The accelerations recorded (with maximum value of about $0.02 \mathrm{~g}$ ) on the cliff during storms show a regular distribution of observed values; this distribution can be correlated with the wave height offshore.

In particular, it would be interesting to carry out a study aimed to analyze the data deriving from accelerometer recordings produced by instrument collocated in different sites and during different periods of the year [3]. The extension of the set of experimental data to a wider range of wave conditions would allow to: 1) check the validity of the presented methodology; 2) deepen both the characteristics of the wave breaking and the cliff-wave interaction; 3) to determine a number of cycles over which instability phenomena of the cliff could occur. 


\section{References}

[1] Carobene, L. (2004) Morfologia, processi e dinamica. In: Coste Marine rocciose, la vita fra roccia e salsedine. Quaderni Habitat.

[2] Cancelli A. e Crosta G. (1993b). Rockfall hazard and risk mapping. Proc. 7th Int. Conf. And Field Workshop on Landslide in Czech and Slovak Republics, Novosad \& Wagner (eds.), Balkema.

[3] D. Amitrano, J.R. Grasso, G. Senfaute (2005) Seismic precursory patterns before a cliff collapse and critical point phenomena. Geophysical Research Letters. Vol. 32 (8). 